\title{
LA PROFESION DE ABOGADO COMO OBJETO DE ESTUDIO
}

I

Una via de reconocida importancia para el entendimiento del derecho viviente en el orden social es la referida al personal que opera con el derecho, vale decir, a los jueces y abogados. En los últimos años ha aumentado notablemente el número de investigaciones emprendidas por sociólogos y hombres de derecho sobre temas como la organización de la profesión de abogado, la evolución de la misma, el comportamiento moral de los abogados, el rol del abogado en el sistema económico y social, la respuesta del público a las decisiones judiciales, la selección de los jueces, la influencia de factores extra jurídicos en sus decisiones y temas semejantes.

Así por ejemplo, en la bibliografía que mantiene al día la revista Law and Society que edita en los Estados Unidos la Asociación para el Estudio del Derecho y la Sociedad, de los 18 acápites en que se clasifican las publicaciones 4 corresponden a la profesión legal, agrupándose muchos libros y artículos bajo dichos subtítulos (1).

La constante preocupación por dicho tópico se manifiesta también en el hecho que uno de los cuatro grandes temas de la moderna Sociología del Derecho es el de los "operadores del derecho" conforme lo señala el profesor Renato Treves (2).

En el presente artículo nos ocuparemos de los diversos enfoques sobre la profesión de abogado contenidos en algunas investigaciones sobre la materia, así como a

1 Law and Society Review, Volume 4, N? 1, August 1969, pp. 123-155.

2 La Sociologia del Diritto, a cura di Renato Treves, Milano, Edizioni di Comunitá, 1966, pp. 24-25. sus posibilidades de empleo en estudios que pudiesen emprenderse en nuestro medio.

A modo introductorio, debemos decir que en el país no existen estudios sobre la profesión de abogado con la orientación que mencionamos. En el fichero que sobre el abogado existe en la Biblioteca de la Facultad de Derecho de la Universidad de San Marcos figuran 62 artículos aparecidos en revistas peruanas. Algunos se refieren a asuntos muy concretos como el ejercicio ilegal de la abogacía, el código de ética profesional c la extensión de beneficios sociales a los abogados. Los publicados bajo título más generales como "El Abogado" - "La Abogacia" tienen contenidos muy diversos, aunque con la común tendencia a reflexionar sobre la misión y la tarea del abogado, estrictamente en el plano del deber ser.

En otros paises latinoamericanos se observa la misma inclinación, abundando los artículos y discursos que se esmeran en reivindicar la buena fama de la profesión, que sueñan con las pasadas glorias de una orden "tan antigua como la magistratura, tan noble como la virtud y tan necesaria como la justicia" (3) o que, como el famoso libro de Ossorio y Gallardo, expresan "el sedimento de (una) existencia profesional" (4). No obstante esto, en algunos de ellos se encuentran consideraciones de interés, que hoy son lugar común en los modernos trabajos sobre la materia.

El siguiente párrafo es una buena muestra de lo que venimos diciendo, puesto que combina una introducción declamatoria con una afirmación final de evidente actualidad:

3 MERCADER, Amílcar. Abogados, Buenos Aires, E. J.E.A., 1960 , p. 31.

4 OSSORIO Y GALLARDO, Angel. El Abogado, Buenos Aires, E.J. E. A., 1956 , p. 11. 
" 'Por eso nuestro papel es grande, maravilloso. Somos el anhelo de la justicia, los apóstoles de la virtud suprema de la vida, los ministros de la paz social. Estamos por encima de la riqueza, de la belleza y de la salud. ¿Puede haber algo más encantador, más emocionante? El abogado tiene que ejercer su profesión con orgullo, con exaltación, con pasión desbordada. ¿Si su alma no late excitada por esos sentimientos de qué le servirá emborronar pliegos y cobrar minutas? Será un ganapán del derecho, podrá ser, quizá, un hombre de ciencia: abogado, no.'

Perclonadme esta larga cita, pero su belleza y realidad resumen a la perfección lo que significa el ejercicio de la abogacía y explican de manera insuperable el porqué de su importancia, y de la obligación permanente de estudio, de sólida formación moral, a la par que de sentido y sensibilidad para captar las mutaciones de la vida que se influencian recíprocamente con las leyes y los principios jurídicos, con que ha de revestirse el abogado" (5).

Otro de los rasgos de algunas de las obras clásicas sobre la materia que han alcanzado gran difusión en América Latina, como la ya mencionada de Ossorio o "Demasiados Abogados" de Calamandrei, es la presentación de una visión tradicional del abogado. Aunque puede decirse en su descargo que dicha concepción tiene su origen en la antigüedad de tales obras, lo cierto es que el resultado práctico es la creación de una falsa impresión. Así, Ossorio califica de absurda la especialización, reprueba la formación de estudios de abogados y recomienda al abogado el matrimonio y la paternidad como fuentes inequívicas de comprensión y serenidad (6). Por su parte, Calamandrei considera una corrupción que el abogado se transforme en mandatario, administrador, agente o socio de su cliente (7).

La existencia de un terreno casi inexplorado, que se acentúa de la confrontación entre lo que se viene produciendo en los Estados Unidos con lo que existe en nuestro medio, ha dado lugar a algunos proyectos de investigación sobre lo que es y lo que hace el abogado en la práctica, emprendidos a través de encuestas. Tal es el caso de la encuesta realizada en Chile por

5 "El Abogado y su Misión", Eugenio Velasco en $E l$ Derecho y los Cambios Sociales, Valparaíso, EDEVAL, 1967 , p. 83.

6 OSSORIO, op. cit., pp. 154-155, 144-45, 210.

7 CALAMANDREI, Piero. Demasiados Abogados, Buenos Aires. E.J.E.A., 1960, p. 107. el Consejo de Decanos con la colaboración del Colegio de Abogados; la patrocinada en Colombia por el Ministerio de Educación, el Ministerio de Justicia, la Asociación Colombiana de Universidades y la Fundación Ford; y la investigación que sobre el mismo tema se está llevando a cabo en el Instituto de Investigaciones Jurídicas de la Universidad Católica del Perú.

\section{II}

Una de las primeras áreas de estudio se ubica en el plano de la simple descripción. ¿Todos los abogados siguen juicios? Si lo hacen, ¿qué proporción de su tiempo dedican a este tipo de trabajo? ¿Qué hacen cuando van al Palacio de Justicia? ¿A qué se dedican los que no litigan, o a qué otra cosa se dedican los que litigan sólo parcialmente? ¿Cómo están organizados los Estudios de abogados? ¿Cómo consiguen sus clientes los abogados? ¿Tienen los abogados buenos ingresos económicos? ¿Todos los que terminan derecho ejercen? Estas son sólo algunas de las preguntas cuyas respuestas pueden dar una idea más o menos clara de la vida profesional del abogado. $Y$ sin negar el valor de consideraciones más trascendentes, quizás sea de mucha utilidad para quien quiere ser abogado que se le diga lo que hace un abogado, junto con las referencias a la justicia con que se asocia a la profesión.

Experimentos más audaces e interesantes son los intentos de calificar esa descripción a partir de una estratificación de los abogados, es decir, de apreciar cómo varía el trabajo y la organización de la vida profesional del abogado según la escala socio-económica que ocupe al interior de la misma. El criterio que más se ha usado para hacer esta estratificación es el tamaño del Estudio. Así Jerome Carlin encuentra que entre los abogados de la ciudad de Nueva York la élite está compuesta por los abogados de los grandes Estudios (21\%), el estrato más bajo por los abogados individuales y los miembros de pequeños Estudios (64\%) y la capa intermedia por los abogados de medianos Estudioss (15\%) (8). Realizada la distribución de los entrevistados en categorias, Carlin procede al análisis de ciertas características de la profesión y al estudio del comportamiento moral de los abogados en función de dicha categorización.

En cuanto a notas distintivas de la profesión, Carlin encontró diferencias sustanciales entre los grupos que

8 CARLIN, Jerome. Lawyers'Ethics, New York, Russell Sage Foundation, 1966, pp. 22-23. 
constituyó: gran Estudio, Estudio mediano, Estudio pequeño y abogado individual. Desde el punto de vista de la clientela, los abogados de los grandes Estudios atienden primordialmente a clientes que se dedican a los negocios: grandes y poderosas empresas de industria pesada y compañías financiadoras; los abogados individuales y los miembros de pequeños Estudios sirven tanto a clientes individuales como a pequeñas empresas, contándose entre éstas sociedades de menor envergadura que las sociedades anónimas y propietarios individuales de negocios dedicados a la venta al por menor, servicios personales, venta de inmuebles y manufacturas ligeras. (9)

Desde el punto de vista del comportamiento moral, también Carlin halló un alto grado de correlación entre la posición del abogado en la escala de estratificación y la conformidad con las normas éticas. Teóricamente hablando, la conducta desviante sigue más o menos el siguiente modelo: a) La posición que se ocupa en la jerarquía social determina el marco de acción del abogado, las situaciones en que actúa. b) Las situaciones, a su vez, presentan frenos u oportunidades que limitan o estimulan la conducta desviante. "Los individuos que ocupan una baja posición en la jerarquía social están bajo gran presión para violar las normas, tienen más oportunidades para hacerlo y son más vulnerables a los azares de su situación." (10). c) La interacción con otros abogados que enfrentan problemas similares conduce a un proceso de justificación de la conducta desviante. d) La disposición interna hacia las normas, como las situaciones, se relaciona con la conducta desviante. Individuos con débil disposición interna, asignados a bajas posiciones en la jerarquia social, están en la situación más favorable para el incumplimiento de las normas.

Dentro de este esquema, los abogados individuales vienen a constituir una especie de proletariado dentro de la profesión. Es el grupo que tiene más dificultades para conseguir clientela; que sufre más que quienes se encuentran en escalones superiores la competencia de personas no entrenadas en la profesión legal; que realiza el trabajo residual, el que dejan los abogados de los estratos superiores; que está más sometido a tensiones, a oportunidades de violar los "standards" éticos de la profesión. Resulta tan interesante el estudio de este sub-mundo profesional consti-

9 CARLIN, op. cit., p. 23.

10 CARLIN, op. cit., p. 171. tuido por los abogados individuales, que el mismo Carlin ha realizado una investigación especificamente sobre ellos en la ciudad de Chicago. Su tipo de práctica es caracterizado de la siguiente manera:

"La práctica de la mayoría de los abogados individuales metropolitanos está consecuentemente confinada a aquellos asuntos (y clientes) residuales que los grandes Estudios no han agotado todavía: (1) materias que no son lo suficientemente grandes o remunerativas para ser manejadas por los grandes Estudios: trabajo de tipo general para negocios y compañías de pequeño a mediano tamaño, transacciones sobre inmuebles (para individuos o pequeños negocios) y asuntos de sucesiones para familias de ingresos medianos; (2) los casos no deseados, el trabajo sucio, aquellas áreas de práctica que tienen asociada un aura de componenda y que envuelven arreglos con clientes y otras personas, sentidas por los grandes Estudios como profesionalmente peligrosas. Esta última categoría incluye impuestos locales, asuntos municipales, daños personales, divorcios y problemas penales" (11).

Asociada con la situación de los abogados individuales, se ha observado una tendencia a la burocratización dentro de la profesión. El número de abogados individuales está declinando en beneficio de la formación de Estudios, mientras éstos aumentan en tamaño. Los Estudios se organizan como una aventura colectiva. Los clientes son clientes del Estudio y no de los abogados que conforman el Estudio; los miembros del Estudio trabajan sólo en los problemas de su especialidad. De este modo, los Estudios pueden ofrecer a sus clientes un alto grado de eficiencia, con la que no pueden competir los abogados individuales.

\section{III}

La estratificación de los abogados por tamaño de Estudio y algunas de las conclusiones inferidas por Carlin en los trabajos mencionados, como por ejemplo la correlación entre tamaño de Estudio y especialización, resulta de menor aplicación en una comunidad de inferior tamaño y características diversas a las de ciudades como Nueva York o Chicago.

Joel Handler ha conducido una investigación en una comunidad mediana, siguiendo las mismas pautas e in-

11. CARLIN, Jerome. Lawyers on their Own, New Jersey, Rutgers University Press, 1962, pp. 17-18. 
cluso el mismo cuestionario de Carlin (12). Handler encontró que el tamaño del Estudio es un indicador de poca importancia en un grupo profesional como el de Prair:e City, compuesto en su totalidad únicamente por 118 abogados en ejercicio.

El sistema utilizado por Handler toma en cuenta los ingresos profesionales del abogado, el poder económico de sus clientes corporativos y la riqueza de sus clientes individuales. Los entrevistados fueron clasificados en tres categorias según sus ingresos: alta, media y baja. De inmediato, se reforzó la clasificación con un puntaje conferido a los abogados según el ingreso de sus clientes. Los ingresos presuntos de los clientes se dividieron también en tres categorías; el entrevistado debía indicar qué porcentaje de sus clientes caía en cada categoría, obteniendo un puntaje de 3, 2 ó 1 tanto para los clientes corporativos como para los individuales. Todos los abogados de bajos ingresos personales tenian clientes de bajos ingresos o de bajos y medianos ingresos combinados; todos los de altos ingresos personales tenian clientes de altos y medianos ingresos; finalmente, los de medianos ingresos personales trabajaban para clientes de medianos ingresos, o para algunos de altos y otros de bajos ingresos. Los abogados que cayeron en la categoría alta, a su vez, fueron subdivididos en altos y de élite. Estos últimos eran los que en adición a tener altos ingresos personales y clientes económicamente poderosos, representaban a las más importantes empresas de la comunidad.

Sugiere también Handler que la especialización puede operar independientemente de la organización en Estudios. Con verdadera agudeza observa que el $70 \%$ de los abogados de Nueva York o son abogados individuales o pertenecen a Estudios pequeños, mientras que el mismo porcentaje de abogados dedica más de la mitad de su tiempo a una sola área de práctica. Esto le permite afirmar que la especialización funcionaria en los grandes centros urbanos aun cuando no hubiese Estudios organizados. "La especialización es -agrega Handler-, en el hecho, el producto de la diferenciación estructural de la comunidad, lo que a su vez produce cantidades de problemas legales divididos en áreas específicas de práctica... Si la profesión legal está deviniendo más especializada, este hecho no debe ser necesariamente medido en correlación con el

12 HANDLER, Joel. The Lawyers and his community, Madison, The University of Wisconsin Press, 1967. declinamiento de la práctica individual; en las grandes ciudades el abogado individual puede ser también un especialista" (13).

\section{IV}

Hay otro tema de mayor sofisticación susceptible de ser investigado y que indaga la correlación existente entre la posición ocupada dentro de la profesión y el origen social de los abogados. La pregunta inicial se plantea en estos términos: ¿de qué depende que un abogado alcance un alto status dentro de la profesión? En los Estados Unidos, los estudios mencionados sugieren que existe una estrecha correlación entre el origen social del abogado, la posición que ocupa dentro de la profesión y las posibilidades de movilidad ascendente al interior de la misma. Hay una especia de determinación que Carlin describe del modo siguiente:

\begin{abstract}
"Las posibilidades de un abogado de alcanzar una posición de alto status en la profesión se fijan en un momento relativamente temprano; el proceso empieza, en efecto, cuando el joven que quiere ser abogado entra al "college". Su religión y clase social determinan en gran medida el "college" en el cual se matricula. La religión, la clase social y el "college" son factores importantes que deciden la calidad de la Facultad de Derecho en la que será admitido. Finalmente, la posición que alcance en la Facultad, la Facultad en la que haga sus estudios, más su religión determinan el tamaño del Estuclio en el que será reclutado" (14).
\end{abstract}

Aunque, como señala Carlin, factores religiosos y sociales se encuentran en la base que determina a qué Facultad de Derecho Ilegará el postulante, un elemento importante de selección entre los que egresan de las Facultades que alimentan el personal de los grandes Estudios es el rendimiento académico. Desde que los mejores alumnos se encargan de la edición de la revista de cada Facultad. los estudiantes de las más prestigiadas Facultades de Derecho que trabajan en la revista tienen prácticamente su sitio reservado en un gran Estudio.

\section{V}

La mera descripción del trabajo: distribución del tiempo, áreas de práctica, obtención de clientes; la estratificación de la profesión de abogados; la evolución

13 HANDLER, op. cit., p. 29.

14 CARLIN, Lawyers' Ethics, p. 29. 
de las características de la profesión como un todo: el monopolio de los grandes Estudios, el declinamiento del abogado individual; el reclutamiento de los abogados en los diversos estratos de la profesión, son facetas de un proceso indagatorio que se ofrece promisorio en nuestro medio, donde solamente tenemos intuiciones de lo que pasa en la profesión.

No sabemos hasta qué punto los Estudios responden a las características que dan lugar al proceso que alguncs autores Ilaman de burocratización: comunidad absoluta de la clientela, agudo proceso de especialización y sujeción a estrictos "standards" de cumplimiento, con el resultado de absorber la parte más productiva de la clientela y permitir que sea posible asociar alto status socio-económico en la profesión con la pertenencia a dichos Estudios. Lo más probable es que aún no se dé esta situación, prevaleciendo el tipo de Estudio conformado sobre la base de una participación en servicios comunes, que viene a constituir un grupo de abogados individuales. $O$ un tipo mixto de Estudio, donde al mismo tiempo que existen clientes del Estudio, cada abogado tiene sus propios clientes. La especialización sería un fenómeno incipiente y la pertenencia a un Estudio o el desempeño de una práctica individual por si solos no serían criterios suficientes de estratificación. El éxito en la profesión estaría fuertemente vinculado al origen socio-económico.

Siendo éste el fenómeno general, existirían algunos Estudios organizados o en proceso de organización según los lineamientos señalados por Carlin. Estos Estudios ya ofrecerian un alto grado de eficiencia y contarían entre sus clientes a los sectores económicamente más poderosos del país. En el futuro, siempre y cuando no se produzcan camb:os que afecten radicalmente el patrocinio legal, este tipo de Estudios absorbería el trabajo mejor remunerado, empujando hacia un proceso de proletarización a los abogados que no pudiesen competir con ellos. En cuanto a reclutamiento, existiría la tendencia a reemplazar criterios de amistad y parentesco con el del buen desempeño académico, escog:éndose los colaboradores entre alumnos o exalumnos de la Universidad Católica y de San Marcos, en ese orden de importancia.

\section{VI}

Aparte de investigaciones como las que han dado lugar a las reflexiones que anteceden, realizadas en ba- se a encuestas, existen intentos a nivel teórico de desentrañar las características sociológicas de la profesión de abogado, así como de situar el papel del abogado en el proceso social.

En términos generales, haciendo abstracción del tipo de sistema legal, el abogado cumple una función de control social. El abogado inpide que su cliente se desvíe de las expectativas que el derecho mantiene respecto a sus sujetos activos y, si se llega a un caso de desviación, ayuda a implementar el proceso que determinará la situación de dicho cliente. En cuanto a lo primero, ello se logra porque el abogado se sitúa, como señala Parsons, "como una especie de amortiguador entre los deseos ilegítimos de sus clientes y el interés social" (15). En cierto modo, representa al derecho más que a su cliente.

También se puede decir lo contrario, que el abogado en ciertos casos, o quizás en muchos, se sitúa entre los deseos legítimos de su cliente y el interés social articulado en el derecho. En otros términos, entre lo que legítimamente reclama su cliente y lo que el derecho como expresión de determinados intereses permite. El abogado resulta casi por definición un representante de la estructura social expresada en el derecho.

De la misma manera, ante intentos de cambio expresados en nuevas leyes, el abogado puede cumplir una función de diseminación y apoyo al cumplimiento de las políticas del gobierno. Aunque también puede contenerlas. Estudios realizados en la India, por ejemplo, han demostrado que en asuntos de reforma agraria los abogados han ayudado a resistir y a socavar la reforma, (16). Queda planteada así una última área de investigación sobre la profesión legal y que toca la función misma de la profesión en la sociedad: ¿a través de qué mecanismos el abogado ayuda a mantener las situaciones expresadas en el derecho y bajo qué condiciones y en qué medida puede el abogado jugar un rol activo en un proceso social revolucionario?

15 PARSONS, Talcott. El Derecho y el Control Social, en Law and Sociology, William M. Evan, ed., New York, The Free Press of Glencoe, 1962, p. 69.

16 GALANTER, Marc. The Study of the Indian Legal Profession, Law and Society Review, Vol. III, No 2 3, November 1968-February 1969, p. 212. 